\title{
A Crustal Section across the Izu-Ogasawara Arc and Trench
}

\author{
By \\ Hiroshi HotTA* \\ Department of Geophysics, Faculty of Science, Hokkaido University, Sapporo
}

\begin{abstract}
The crustal structure across the northern part of the Izu-Ogasawara arc and trench system was investigated by seismic refraction and reflection methods. A schematic crustal section across the island arc and trench along latitude $32^{\circ} \mathrm{N}$ is presented. The $5.4-\mathrm{km} / \mathrm{sec}$ layer in appreciable thickness was detected in the narrow area between the trench and the Shichito-Iwojima ridge as same as in the Kuril arc and the southern part of this arc in the junction to the Mariana arc. If the $5.4-\mathrm{km} /$ sec layer was concerned with the outer arc formation in the southern double arc, south of $29^{\circ} \mathrm{N}$, then the presence of the layer may indicate the continuation of a recent non-volcanic outer arc not reflected on the topography to the north.

There is inferred a fault which reaches down to the mantle under the ridge side slope of the trench. The fault is suggested by a study on the force mechanism in the island arc and trench systems and supported by a recent study on the spacial distribution and focal mechanisms of shallow to deep earthquakes.
\end{abstract}

\section{$\S 1$. Introduction}

During May, 1966, four seismic refraction profiles were recorded parallel to the topography in the northern part of the IzuOgasawara (Bonin) arc and trench, as part of the Upper Mantle Project (Figure 1). Several months later a seismic reflection traverse (seismic profiler) was made along latitude $32^{\circ} \mathrm{N}$ from the Pacific Ocean basin to the Shikoku basin in the Philippine Sea in order to intersect approximately the middle points of refraction profiles. These data supplement the earlier studies of LUDWIG et al. (1966) who made two refraction profiles on the northern Izu-Ogasawara arc near Hachijo island and a number of seismic profiler crossings. Other refraction measurements were made along latitude $23.5^{\circ} \mathrm{N}$ in the junction of the Izu-Ogasawara and the Mariana arcs and trenches by MurAUCHI et al. (1968). Their work produced a schematic crustal section of the island arc and trench in this vicinity.

* Now at Rikagaku Kenkyusho (The Institute of Physical and Chemical Research), Yamato-Machi, Saitama.
The major physiographic features in the concerned area are illustrated in Figure 2. The Izu-Ogasawara arc represents the northern half of the Honshu-Mariana arc which extends southward from a major graben (Fossa Magna) in the Honshu, Japan, towards the Mariana islands. This arc, essentially, consists of three ridges: the Nishi-Shichito ridge of series of seapeaks and banks (recent volcanic activity in the ridge has not been reported) on the west, the central ShichitoIwojima ridge of active volcanic islands chain, and the Ogasawara (Bonin) ridge of now non-volcanic islands on the east. However, these three ridges are not continuous throughout the arc length. The Nishi-Shichito ridge becomes less distinct south of $29^{\circ} \mathrm{N}$ and is difficult to recognize. On the contrary, the Ogasawara ridge can be recognized well south of $29^{\circ} \mathrm{N}$, but its continuity to the north has never been established (Figures 1 and 2). Consequently, the southern half of the IzuOgasawara arc shows a typical double arc system arrangement, however, the northern half appears to be unusual double arc or modified single arc system, i.e., physiographic features are arranged in the sequence of a 

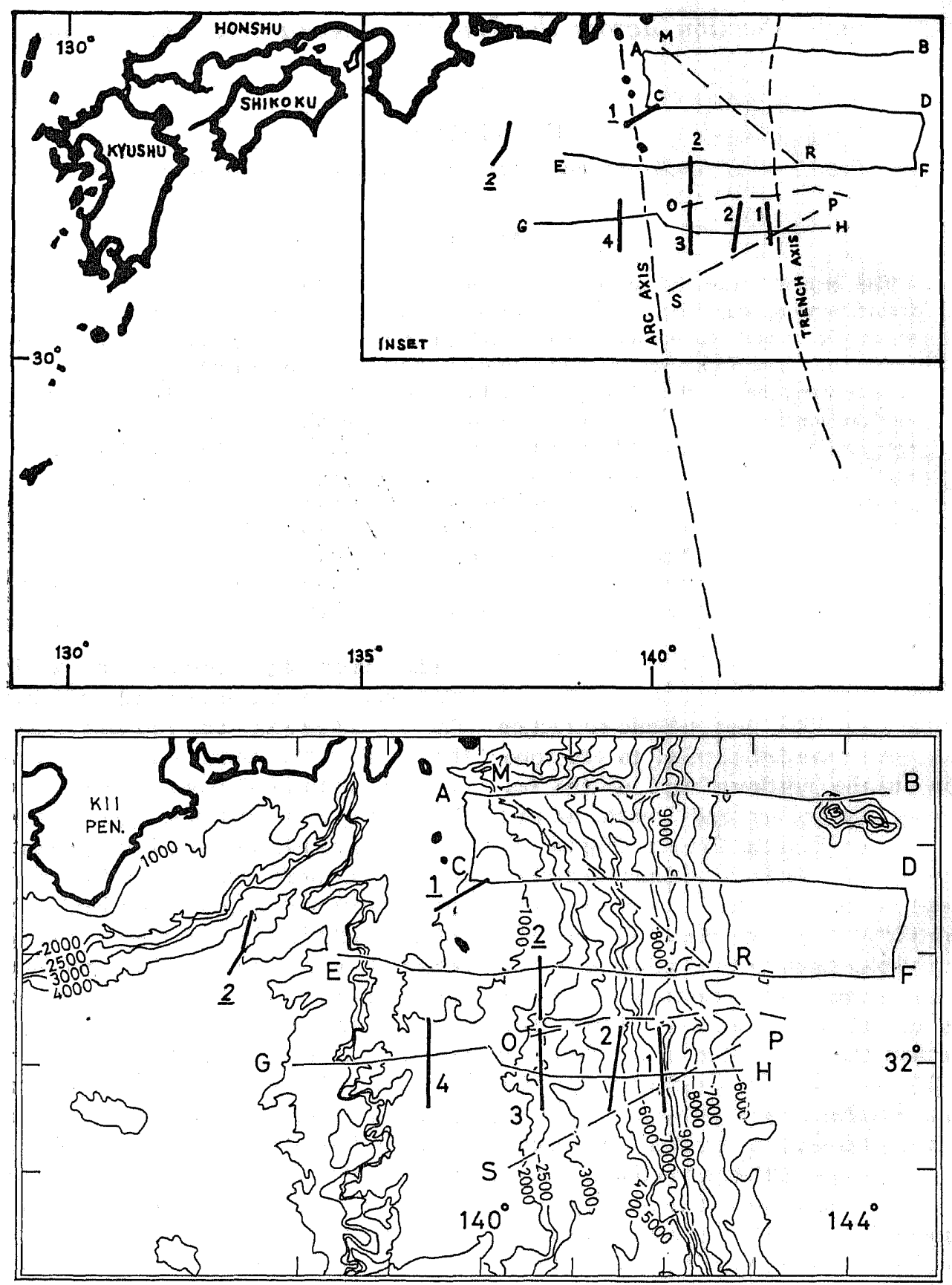

Fig. 1. Geographic locations of refraction profiles and seismic profiler tracks. Isobaths are taken from the Japanese Bathymetric Chart No. 6302. Thick solid lines and number designations refer to refraction profiles. The locations of prior seismic refraction profiles are designated by underlined numbers. Thin solid lines with alphabetic letters $A$ through $H$ show the profiler tracks in 1965 and 1966. Locations of prior profiler tracks made by Ludwig et al. (1966) are shown by broken lines with letters $\mathrm{M}, \mathrm{R}, \mathrm{O}, \mathrm{P}$, and S. 


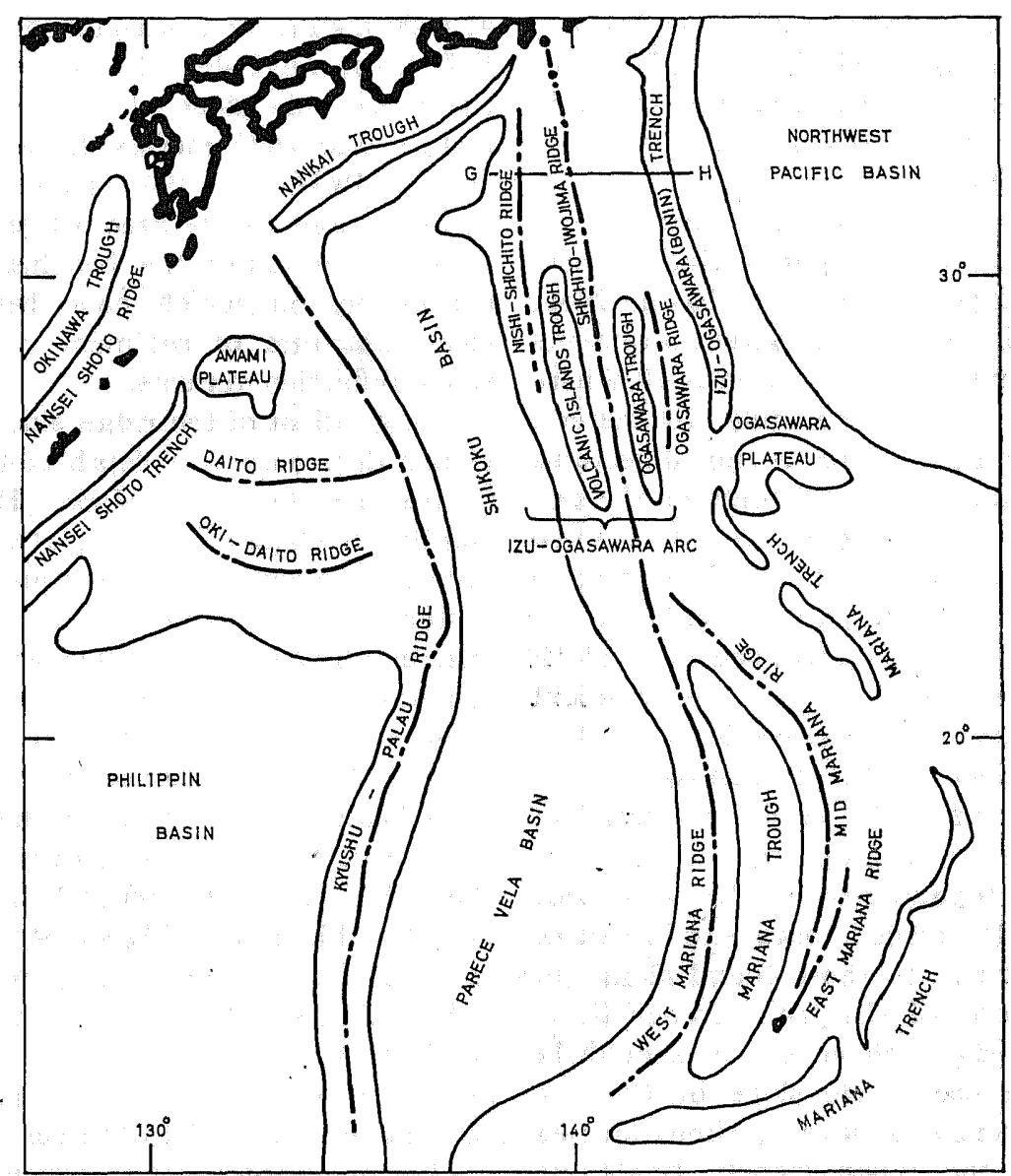

Fig. 2. Main physiographic features in the concerned area (adopted from the Explanatory Text of the J. H. O. Bathymetric Chart 6302 (1966)).

trench, an active volcanic ridge followed by a non-volcanic ridge.

The techniques of seismic refraction measurements and the method of interpretation are essentially the same as described by several authors (RAITT, 1952. OFFICER et al., 1959. DEN, 1962. SHOR, 1963). The techniques and instruments of continuous seismic reflection profiling are essencially the same as those developed at Lamont-Doherty Geological Observatory (EWING and TIREY, 1961. EWING and ZAUNERE, 1964. HOTTA, 1967).

Designations of physiographic features are adopted from the explanatory text of Japanese Bathymetric Chart 6302 (Japanese Hydro- graphic Office, 1966), and also several other papers are referred to in the description (HESS, 1948. TAYAMA, 1952. DIETZ, 1954).

\section{§2. Seismic Reflection Measurements}

Continuous shipboard measurements of the bathymetry and sediment thickness in the northern part of the Izu-Ogasawara arc and trench were carried out in 1965 and 1966. Prior to those measurements, three other profiles were made in the same area. The tracks of profiling and results are shown in Figures 1, 3-a, and 3-b.

The layer indicated with hatcheres in the area east of the axis of the trench exhibits very strong and highly reverberent reflec- 
tions. This layer is identified as layer 2 (oceanic basement) of velocity about $5-\mathrm{km} / \mathrm{sec}$ from the refraction measurements made in the northwest Pacific Ocean basin by LuDWIG et al. (1966).

In general, acoustically transparent sediments, a few tenths of seconds thick, overly the basement layer in the ocean basin. Most thick accumulation of transparent sediments are observed near $143^{\circ} \mathrm{E}$ (section $\mathrm{A}-\mathrm{B}$ ) where the thickness is approximately 700 meters, i.e., 0.7 seconds. There is no detectable amount of transparent sediments on the seamounts, e.g., the "Daisan" (No. 3) Takuyo seamount located at about $144^{\circ} \mathrm{E}$ in section A-B. The remarkable gaps of both the sea floor and basement are observed near $144^{\circ} \mathrm{E}$ and $144.5^{\circ} \mathrm{E}$ in section $\mathrm{E}-\mathrm{F}$. The gradient of these features is comparable to that of the steeper slope of the trench wall, i.e., about 10 degrees. The scale and trend of these features are not known.

The rough topography on the ocean side (east) slope of the trench appears to be caused by faults, similar to those found along the ocean side slope of the Japan trench (LUDWIG et al., 1966). However, it should be noted that the ocean side slope of the IzuOgasawara trench is several times steeper than that of the Japan trench (IWABUCHI, 1968).

The flat floor of the trench is a fill of transparent and (or) stratified sediments (sections $\mathrm{A}-\mathrm{B}, \mathrm{G}-\mathrm{H}, \mathrm{M}-\mathrm{R}, \mathrm{O}-\mathrm{P}$, and $\mathrm{S}-\mathrm{P}$ ). The flat floor of the trench in section $C-D$ indicates it is probably formed by similar sedimentation, although the sediments were not penetrated. In section E-F the trench bottom is $\mathrm{V}$-shaped. There is no appreciable amount of sediments and the basement layer may crop out to the sea floor.

The ridge side (west) slope of the trench has a covering of opaque sediments; no subbottom reflection returns are observed. The opaque sediments are designated by small dots in Figure 3-a. There are two conspicuous benches on this slope; one at the depth of about 7500 meters or 10 seconds (sections $\mathrm{C}-\mathrm{D}, \mathrm{E}-\mathrm{F}$, and $\mathrm{O}-\mathrm{P}$ ), and the other at 6800 meters or 9 seconds depth (sections $\mathrm{E}-\mathrm{F}, \mathrm{G}-\mathrm{H}$, and $\mathrm{S}-\mathrm{P})$. These two benches on the ridge side slope at depths of $6200-6500$ meters and 8000 meters have been pointed out by IWABUCHI (1968) from echo-sounder investigations in the area between $33^{\circ} 15^{\prime}$ and $33^{\circ} 50^{\prime} \mathrm{N}$. Actually the benches are narrow depressions in which have been deposited small amounts of sediment which produce weak reflection returns.

The gradient of the ridge side slope of the trench decreases at a depth of 4 to 6 seconds to become the upper slope. However, the significant change in slope, the slope break, occurs at about 3 to 4 seconds depth. The pattern of sedimentation also changes from that depth toward shallower water. No correlatable reflectors are detected under the ridge side slope of the trench except under the bench, as mentioned above. However, there is a distinct stratified sequence of sediment beneath the more gentle slope toward the ridge crest. In general, the uppermost layer in this area is highly stratified except in section $C-D$ (more transparent in section C-D). There is a deep-sea terrace at 3-4 seconds depth in sections $\mathrm{E}-\mathrm{F}, \mathrm{G}-\mathrm{H}$, and S-P. Sediment bedding under the terrace is approximately parallel to the sea floor.

The topography along section C-D differs. from that of the other sections. There is no. terrace-like feature on the upper slope only bottom irregularity in the area shallower than 3 seconds. This irregularity of the sea floor is probably caused not by faulting but by erosion or some other phenomena to. change only the bottom shape, because no. such features are found in deeper reflectors.

Many seamounts or seapeaks suggestive of the past or present active volcanism in the: western crestal zone of the island arc are shown in sections E-F and G-H. Other interesting features in the crestal zone are the small depressions observed near $139^{\circ} 39^{\prime} \mathrm{E}$ in section E-F and $139^{\circ} 45^{\prime} \mathrm{E}$ in section G-H. The sea floor in the depression slopes to the east and the eastern boundary of the depression is sharply bounded, as if by moderately high angle faults. Sudden changes in water 


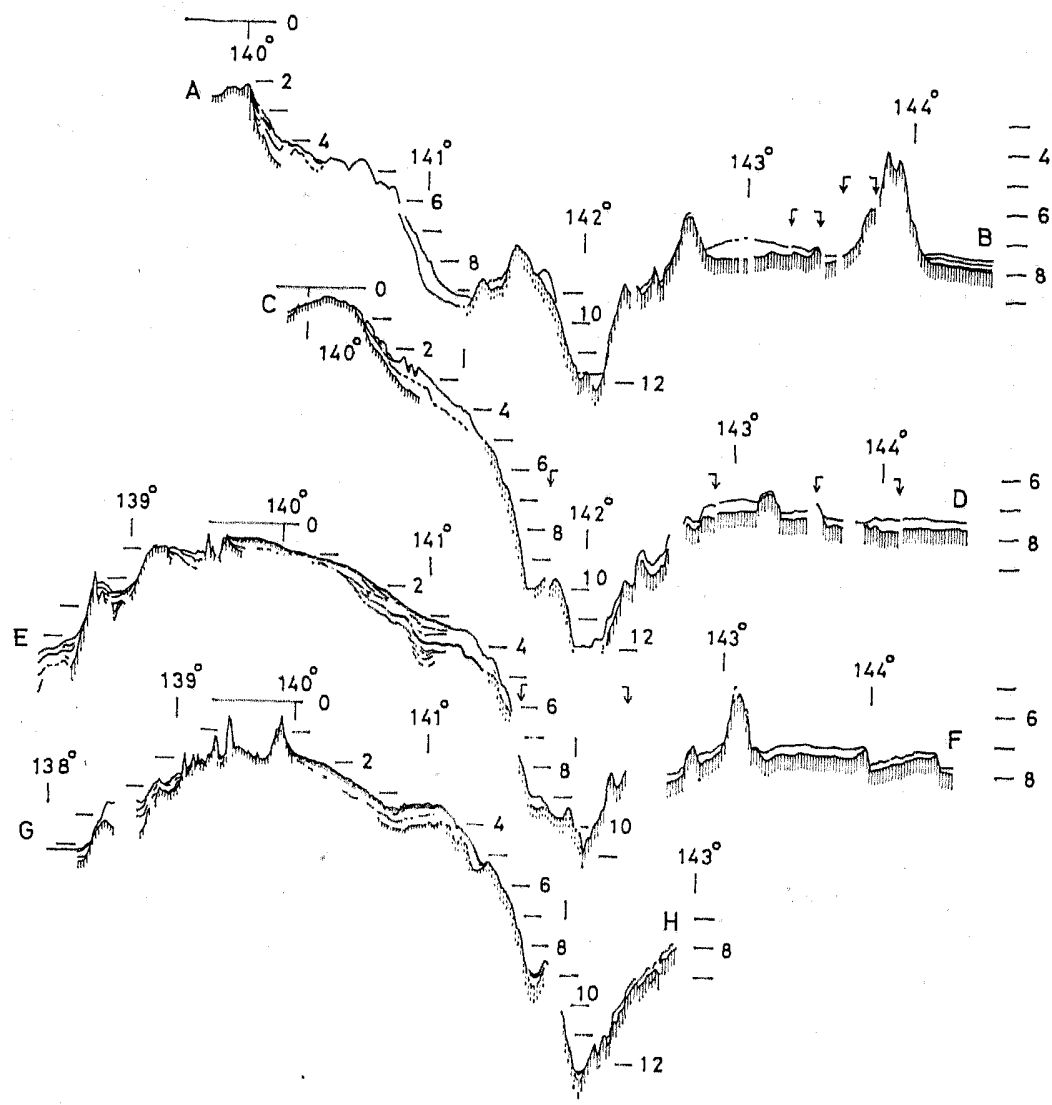

Fig. 3-a

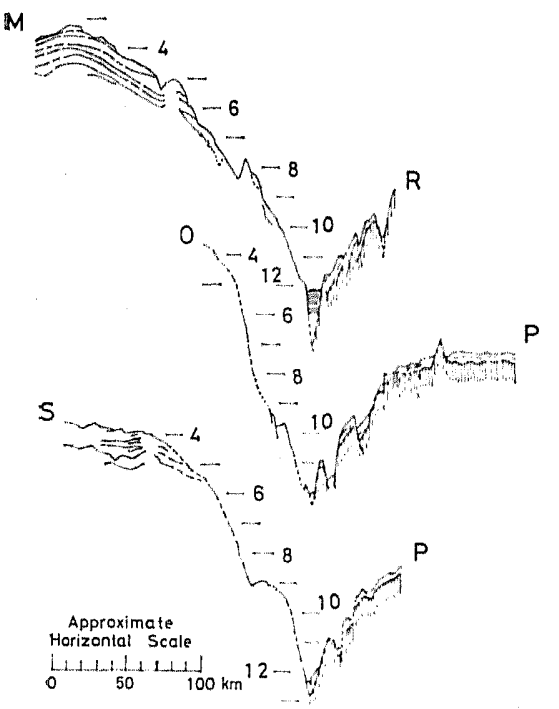

Fig. 3-b
Fig. 3. Line drawings of seismic profiler investigations in 1965 and 1966 are shown in Figure $3-\mathrm{a}$, and results of Ludwig et al. (1966) in the same area are reproduced in Figure $7-\mathrm{b}$. The vertical scale is two way reflection time in seconds. The horizontal scale in Figure 7-a is given in degrees of longitude, but in Figure 7-b in kilometers. However, approximate vertical exaggerations in both figures are nearly same to $25: 1$. The vertical exaggeration varies from place to place, especially in Figure 7-a, because horizontal scale depends on the ship's speed, 8-10 knots. The range shown between arrows in Figure 7-a were profiled with small explosive shots fired on a one or three minutes schedule, during a time the pneumatic sound source was being repaired. Therefore, fine structure in sediments are not as clear in these ranges as are in those made with the airgun. 
depth exceed 500 meters, about 0.7 seconds in reflection time, at the east end. MOGI (1968) reported that several depressions are arranged in a line along the western side of the crest and pointed out that linear arrangement of volcanic islands and depressions sided with them is one of the characteristics of the Izu-Ogasawara arc. No detectable amount of sediment are observed in the center of the depression in section $\mathrm{E}-\mathrm{F}$ and in the depression in section $\mathrm{G}-\mathrm{H}$, although some amount of sediments are obsesved in the western part of the depression in section $E-F$.

The shallow area in section C-D near $140^{\circ} \mathrm{E}$ is called the Shinkurose bank. The bank is formed by material which gives rise to strong and reverberent reflection returns from the sea floor. Exposure of rocks on the bank is described in Japanese charts (e.g., J.H.O. Chart No. 1007), but the rock type is not known.

The westernmost part of the island arc, between $139^{\circ} \mathrm{E}$ and the 3000 meters isobath in Figure 1, is called the Nishi-Shichito ridge (Figure 2). This ridge has several linear trends of seapeaks, banks and shoals alingned in a northeast-to-southwest direction. The sedimentary structure of this ridge is shown in sections $\mathrm{E}-\mathrm{F}$ and $\mathrm{G}-\mathrm{H}$. In both sections the character of the ridge is clearly displayed. A seapeak is observed at the western side in section $\mathrm{E}-\mathrm{F}$, behind which there is a thick accumulation of sediments. In section $\mathrm{G}-\mathrm{H}$ very thick transparent sediments are ponded behind a basement ridge near $138^{\circ} 20^{\prime} \mathrm{E}$, designated by hatchers. The thickness of transparent sediments here exceeds possibly 1 second (about 1 kilometer). Transparent sediments observed on the Nishi-Shichito ridge continue westward and down into the Shikoku basin.

The acoustical properties of sediments seem to be slightly different on both sides of the island arc except in section C-D. Sediments accumulated east of the crest are highly stratified and parallel to the sea floor. On the contrary, sediments found west of the crest are more transparent and their thickness vary greatly from place to place. Rough- ness of the topography on this side is caused by basement exposures. The different acoustical properties may indicate that different sedimentation rates or mechanisms are acting on each side.

\section{§3. Seismic Refraction Measurements}

Profiles were recorded along the axis of the trench, on the ridge side (west) slope of the trench, on a deep-sea terrace lying at 2500-3000 meters depth, and approximately along the crest of the Shichito-Iwojima ridge (Figure 1). The time-distance graphs, the topography along the profiles, and the deduced velocity structures, and explanations on each profile are presented in the appendix. The locations of profiles, the velocities and thicknesses of layers in the structure are tabulated in Table 1.

\section{§4. Some Discussions on the Crustal Structure}

Velocities and thicknesses derived from refraction measurements are plotted on profiler section $\mathrm{G}-\mathrm{H}$ and shown in Figure 4. In this figure the topography and structure are extended to the Shikoku basin and the northwest Pacific Ocean basin. The sedimentary layer, obtained by profiler measurements, is designated by hatching.

The crust under the ocean side slope of the trench is assumed to be normal oceanic. Beneath the ridge side slope of the trench the crustal structure is not normal oceanic, but modified through inclusion of the 3.7and $5.4-\mathrm{km} / \mathrm{sec}$ layers. The lower ridge side slope of the trench has thick low-velocity materials of velocity $3.7-\mathrm{km} / \mathrm{sec}$. The 3.7 $\mathrm{km} / \mathrm{sec}$ layer appears to be different from the $2.7-\mathrm{km} / \mathrm{sec}$ layer and the $4.5-\mathrm{km} / \mathrm{sec}$ layer found on the upper part of the slope; that is, the $3.7-\mathrm{km} / \mathrm{sec}$ material seems to be confined to a narrow area. This suggests that the $3.7-\mathrm{km} / \mathrm{sec}$ layer was not produced by simple outbuilding of sediments and the formation of the bench is not caused by simple faulting. Thick low-velocity sediments beneath the lower ridge side slope of the trench are found in other trenches (OFFICER et al., 1959, KosminskayA et al., 1963, LUDWIG et al., 
Table 1. Locations of profiles, thicknesses and velocities of each layer and depths to the Mohorovicic discontinuity.

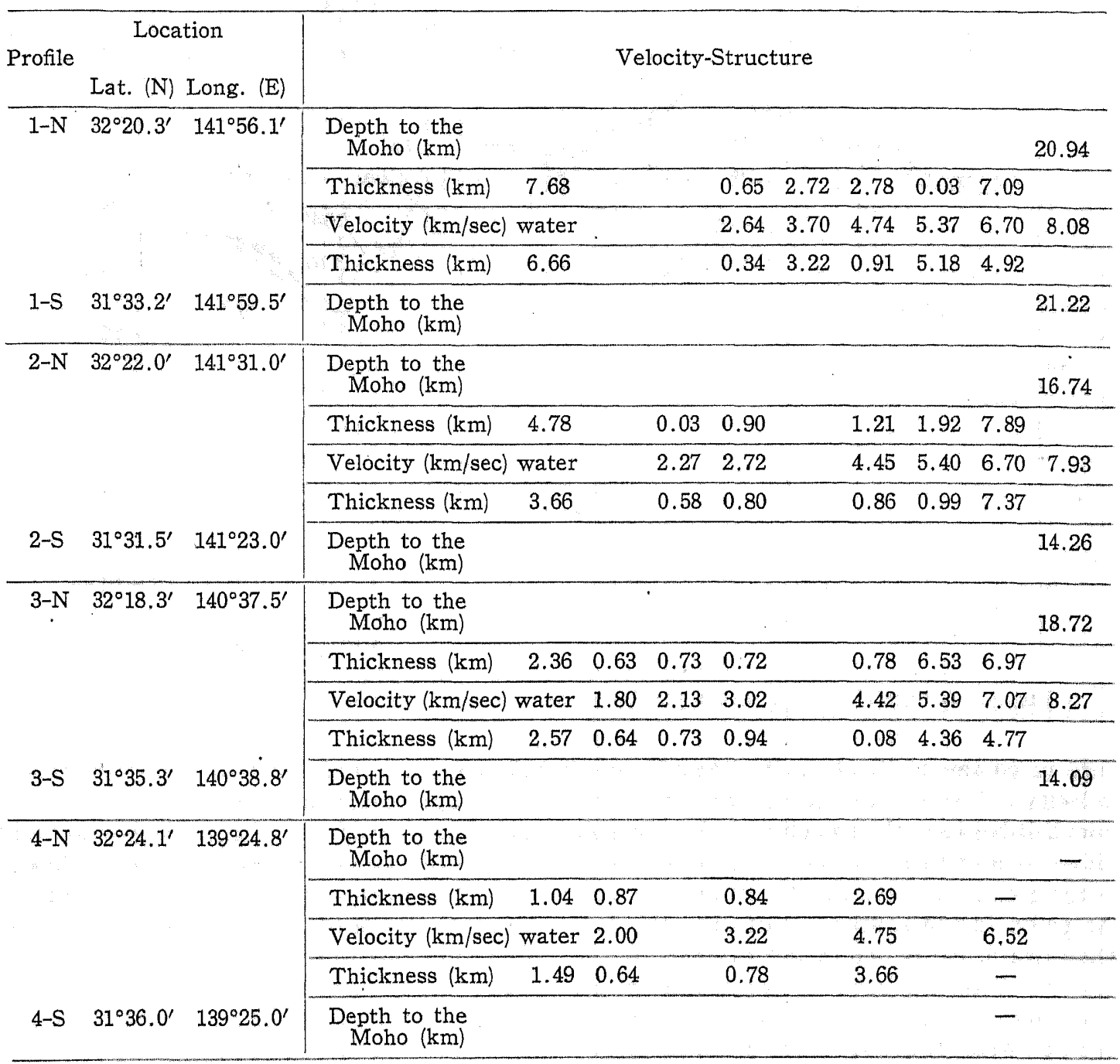

1966, Murauchi et al., 1968). Certainly, some part of the material have been transported downslope along the ridge. However, another possibility is that the sediments may be the result of piling up of scraped sediments from the Pacific Ocean plate being underthrusted beneath the island arc, as required by the hypothesis of sea floor spreading (LE PICHON, 1968. IsACKS et al., 1968. EWING et al., 1968). The opaque layer observed in the profiler records along the ridge side slope corresponds to the layers of $2.6-$ to $3.7-\mathrm{km} / \mathrm{sec}$ in refrac- tion measurements.

The $5.4-\mathrm{km} / \mathrm{sec}$ layer is confined to the eastern side of the arc. This layer is not found in profile 4 along the western side of the crest. Where the $5.4-\mathrm{km} / \mathrm{sec}$ layer is quite thick, both the $7-\mathrm{km} / \mathrm{sec}$ layer and the overlying $4.5-\mathrm{km} / \mathrm{sec}$ layers are remarkably decreased in thickness. When this crustal structure is compared with that of the southern. part of this island arc (MURAUCHI et al., 1968) and the Kuril-Kamchatka arc (KOSMINSKAYA et al., 1963), it is found that there is one fea- 


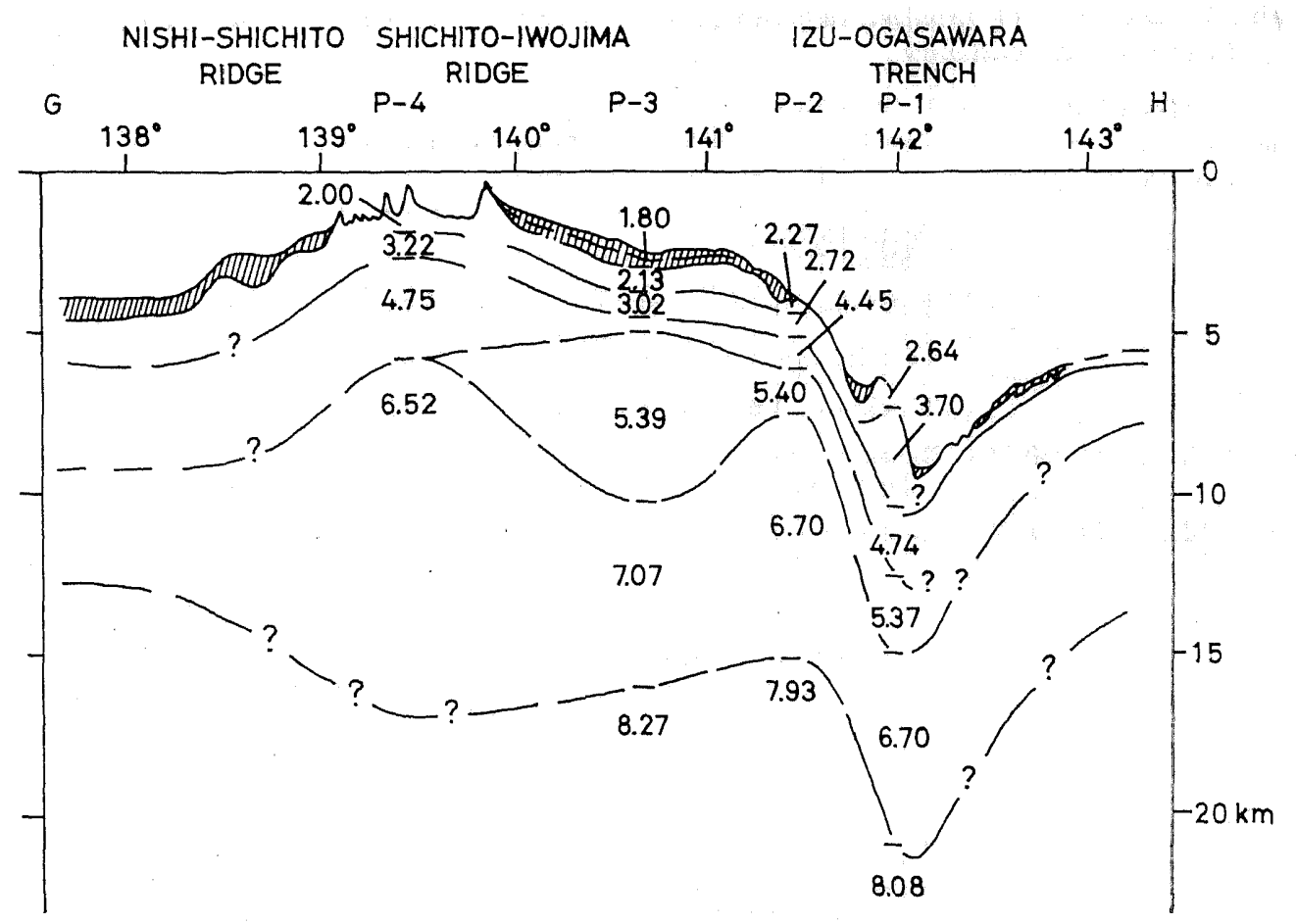

Fig. 4. A crustal section across the Izu-Ogasawara arc and trench along latitude $32^{\circ} \mathrm{N}$.

ture in common. Each region has a layer of velocity $5.0-$ to $6.0-\mathrm{km} / \mathrm{sec}$ confined in a narrow belt between the trench and the volcanic ridge, where there should be a non-volcanic outer arc, if they are the double arc systems. Actually, in the southern half area the IzuOgasawara arc is double arc system. If the 5.0 - to $6.0-\mathrm{km} / \mathrm{sec}$ layer between the trench and volcanic ridge is considered to be concerned with the outer arc formation, the continuity of the outer arc which is not reflected on the topography may be suggested.

Profile 2 of LUDWIG et al. (1966) made just north of profile 3 gave a similar velocity section. They presented two crustal models; one a three layer solution of velocities 2.1-, $5.3-$, and $6.4-\mathrm{km} / \mathrm{sec}$, and the other a two layer solution in which a $5.7-\mathrm{km} / \mathrm{sec}$ layer is overlain by low velocity sediments. There is a 2-4 kilometers disagreement in depths to interfaces between profile 2 of LUDWIG et al. and profile 3 . Unfortunately, the former profile was not reversed, hence the results may contain some uncertainties. Otherwise, the disagreement in depths may be the result of faulting, if a submarine canyon located between the profiles (Figure 1) was devoloped along a fracture. The submarine canyon cuts the eastern side of the arc about 600 meters and trends east-west to the trench (IWABUCHI, 1963).

The velocity structure west of the crestal zone is similar to that in the Shikoku basin. Therefore, the same type of crust as that in the Shikoku basin may be deformed upward in this area, at least the upper part of the crust. This is suggested by the force mechanism of tectonics in the island arc and trench systems (HoTTA, 1970).

The $2.0 \mathrm{~km} / \mathrm{sec}$ sedimentary layer, generally, is well detected by the seismic profiler. It was measured over an extensive area from the Shikoku basin to the edge of the deep-sea terrace on the eastern side of the island arc. However, it is absent in the depression area near the crest of the ridge in the profiler 
records. Here, there are no detectable amount of sediments seen in the profiler records, but the refraction measurements indicated about 0.7 kilometers of low-velocity materials. The sediments in the depression may have somewhat different composition than those on either sides.

Beneath the low-velocity sediments there is a layer of velocity about $3.0-\mathrm{km} / \mathrm{sec}$ which is measured continuous from the trench to the crest of the arc, and continuous into the Shikokt basin. The velocity in this layer seems to decrease from $3.22 \mathrm{~km} / \mathrm{sec}$ on the crest to $2.64-\mathrm{km} / \mathrm{sec}$ in the trench and 3.06 $\mathrm{km} / \mathrm{sec}$ in the Shikoku basin. A similar change in velocity of the $3-\mathrm{km} / \mathrm{sec}$ layer was noted by DEN (1967) in the southern part of this arc and trench from the measurements of MURAUCHI et al. (1968).

The high-velocity crust, the $5.4-$ and $7-\mathrm{km} /$ sec layers, and the uppermost mantle show abrupt change of depths between the trench (profile 1) and the deep-sea terrace (profile 2). The gaps of the depths are approximately 7 kilometers for each interface. The distance between the profiles is about 60 kilometers, so the gradient of each interface is $5-8$ degrees. The value is almost same as that of the ride side slope of the trench.

The force mechamism of tectonics in the island arc and trench systems was studied by HotrA (1970). He obtained "the isostatic pressure-depth relationship of the Moho" by use of about 200 refraction data in the stable area. By the pressure-depth relationship the isostatic state across the island arc and trench systems were investigated. Through the investigations it was revealed that tectonics in the island arc and trench systems are essentially held by a pair of forces in opposite directions, $i . e$., downward force of about $1000 \mathrm{~kg} / \mathrm{cm}^{2}$ is acting on the crust-mantle in the trench and upward force of about 500 $\mathrm{kg} / \mathrm{cm}^{2}$ on the crust-mantle of the island arc. In the Izu-Ogasawara arc and trench it was found that there is the pressure deficiency estimated to exceed $1000 \mathrm{~kg} / \mathrm{cm}^{2}$ in the trench axis but the crust-mantle under the deep-sea terrace is in isostatic equilibrium. Moreover, that the crust-mantle under the arc area is possibly out of isostasy so far as the Moho is shallower than 20 kilometers was suggested. Consequently, the crust-mantle between the trench and the terrace is considered to be received a shearing force of about $1300 \mathrm{~kg} / \mathrm{cm}^{2}$. The magnitude of the force may cause faulting in the crust-mantle in the area, because the breaking strength of the crust is considered to be approximately $1000 \mathrm{~kg} / \mathrm{cm}^{2}$ (e.g., HEISKANEN and VENING MEINESZ, 1958). Hence, the gaps of depths in the high-velocity crust and the mantle are interpreted to be caused by faulting there. Actually, the recent study on the spacial distribution and focal mechanism in this region (KATSUMATA and SYKES, 1969) seems to support the faulting. The seismic zone from shallow to deep earthqakes is dipping westerly from the trench. Focal mechanisms of shallow earthquakes occured between the trench and the terrace is shown as the thrust fault type.

\section{Appendix}

The time-distance graphs for profiles 1 to 4 are presented in Figures 5 to 8 . The distance between the receiving positions and shot points is given in seconds of direct water wave travel time, and inverse slopes of the velocity lines are in kilometers per second. Water depths in the topography along the shooting tracks and the thickness of refracting layer in the crustal structure are in kilometers.

\section{PROFILE I}

This is a reversed profile which was intended to be make along the axis of the trench. However, the actual location of the profile was oriented slightly towards the ridge side, and the measurements were made instead on a bench located between 6500 meters and 8000 meters depth on the ridge side slope of the trench. Topographic corrections were applied to a sloping base line between 6.66 and 7.68 kilometers depth.

The $2.64-\mathrm{km} / \mathrm{sec}$ layer is determined from the apparent velocities shown with the 2.69. $\mathrm{km} / \mathrm{sec}$ line at the north and the $2.60-\mathrm{km} / \mathrm{sec}$ line at the south end. Both velocity lines 


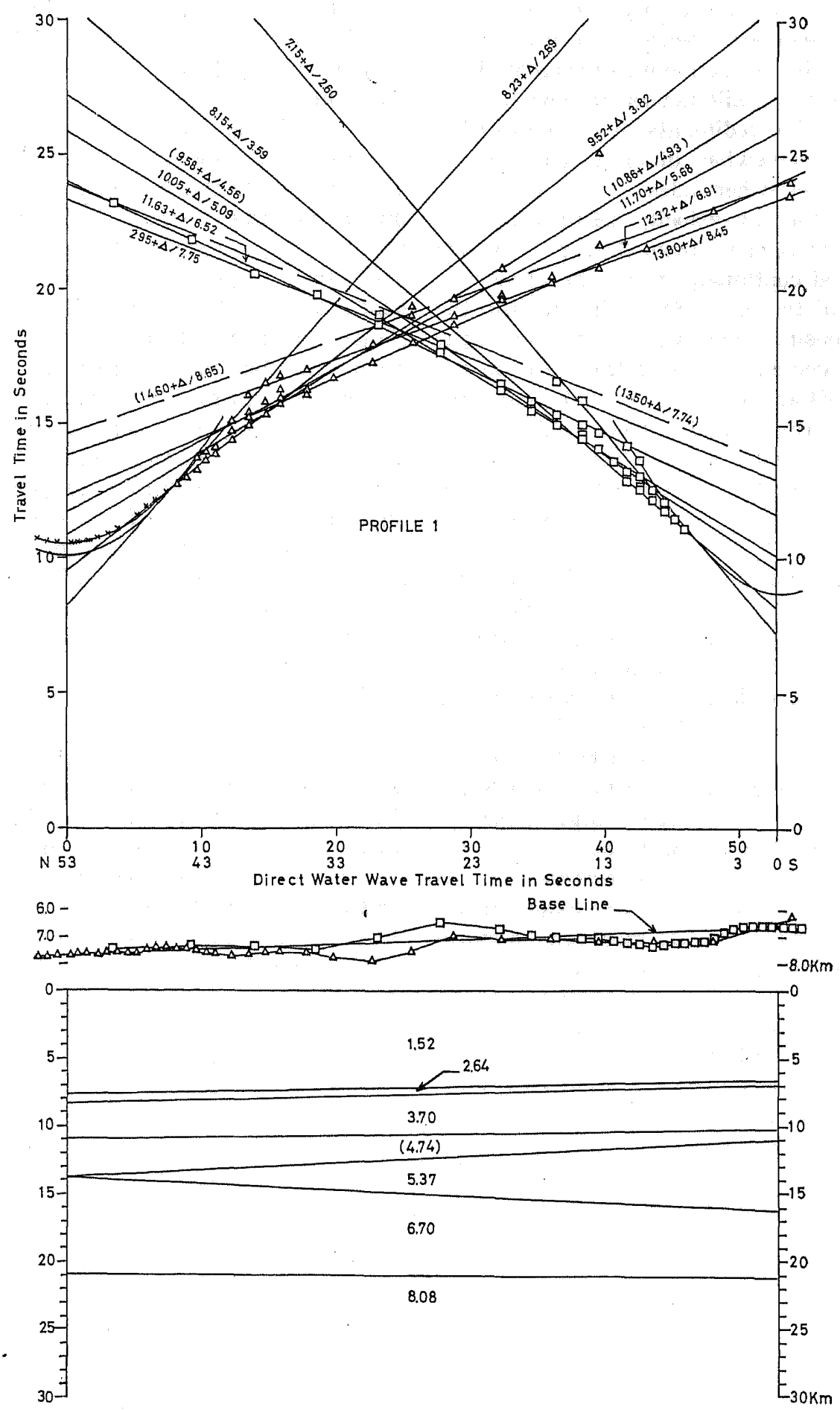

Fig. 5. Profile 1 
are determined mainly by later arrivals and tangency to the curves of first sea-bottom reflections (the $R_{1}$ curve). This velocity determination is in agreement with a $\mathrm{X}^{2}-\mathrm{T}^{2}$ solution for interval velocity (Drx, 1955), $3.0-\mathrm{km} / \mathrm{sec}$, obtained from subbottom reflections recorded at the north end.

The $3.70-\mathrm{km} / \mathrm{sec}$ layer is well determined by many first arrivals recorded at both ends of the profile and tangency to the sub-bottom reflection curve at the north end. At the south end, sub-bottom reflection are not detectable. However, the best line fit of first arrivals intersects the $R_{1}$ curve. This suggests that there is a small amount of lowvelocity sediments with velocity $2.64-\mathrm{km} / \mathrm{sec}$ overlying the $3.70-\mathrm{km} / \mathrm{sec}$ layer on the southern end.

The $4.74-\mathrm{km} / \mathrm{sec}$ layer is determined mostly several later arrivals. Only one first ar. rival interpreted as originating in this layer was observed in 15.8 seconds of distance at the north end of the profile. Therefore, the velocity is questionable and is given in parentheses in the figure.

The $5.37-\mathrm{km} / \mathrm{sec}$ layer is determined by three first arrivals and some later arrivals at the south end, but similar such first arrivals are not observed at the other end except for some later arrivals. Therefore, it is assumed that the $5.37-\mathrm{km} / \mathrm{sec}$ layer is thick under the ridge side slope of the trench, i.e., thick at the south end of the profile, and very thin or absent near the axis of the trench, $i . e$. , thin at the north end of the profile.

The $6.70-\mathrm{km} / \mathrm{sec}$ layer is well determined by many first arrivals and a few later arrivals recorded at both ends of the profile.

The $8.08-\mathrm{km} / \mathrm{sec}$ layer, the mantle, is determined mainly by a few first arrivals and several later arrivals recorded at the north end. The velocity line determination for the reverse half of the profile is difficult because the arrivals observed beyond 43 seconds range are plotted on the line of $6.52-\mathrm{km} / \mathrm{sec}$. Earlier phases could not be picked on these records. The first arrival recorded at 39 seconds is weak but is plotted approximately 0.15 seconds earlier (below) than the $6.52-\mathrm{km} / \mathrm{sec}$ line. Hence, the $7.75-\mathrm{km} / \mathrm{sec}$ line passing through this first arrival and some later arrivals recorded in the shorter range is determined. Here, it is assumed that refracted energy from the Mohorovicic discontinuity is too weak to be detected by last two records.

Another interpretation is that refracted energy from the Mohorovicic discontinuity are not observed as first arrivals throughout the profile length. This interpretation is indicated by broken lines drawn through several later arrivals on the time-distance graph. The calculated depth to the mantle is deeper by about 4 kilometers than that indicated in the structure section. However, alternative interpretation is based on yet weaker evidence than the other, because all later arrivals are questionable, and there still are first arrivals recorded at the north end to be interpreted. PROFILE 2

This profile was recorded on the ridge side slope of the trench. There is an appreciable difference in water depth between the forward and reverse half of the profile despite slight drift of the recording vessels. Moreover, the topography along each shooting. track is rather rough. Therefore, a sloping base line between 3.66 and 4.78 kilometers. was fitted for topographic corrections.

The $2.27 \mathrm{~km} / \mathrm{sec}$ and the $2.72-\mathrm{km} / \mathrm{sec}$ layers. are determined solely by later arrivals. The velocity line of the $2.72-\mathrm{km} / \mathrm{sec}$ layer at the north end is tangent to the $R_{1}$ curve, but the corresponding velocity line at the south end intersects the $R_{1}$ curve. This suggests that the $2.72-\mathrm{km} / \mathrm{sec}$ layer crops out at the north end, and is overlain by lower velocity material at the south end. This is supported by seismic profiler observations; the sediments along the ridge side slope of the trench are acoustically opaque, but in the area where water depths are shallower than about 4 kilometers (about 5.4 seconds in reflection time) finely stratified sediments over the opaque layer are observed (section G-H in Figure 3-a). The velocity lines of the topmost sedimentary layer are determined by some later arrivals and tangency to the $R_{1}$ 

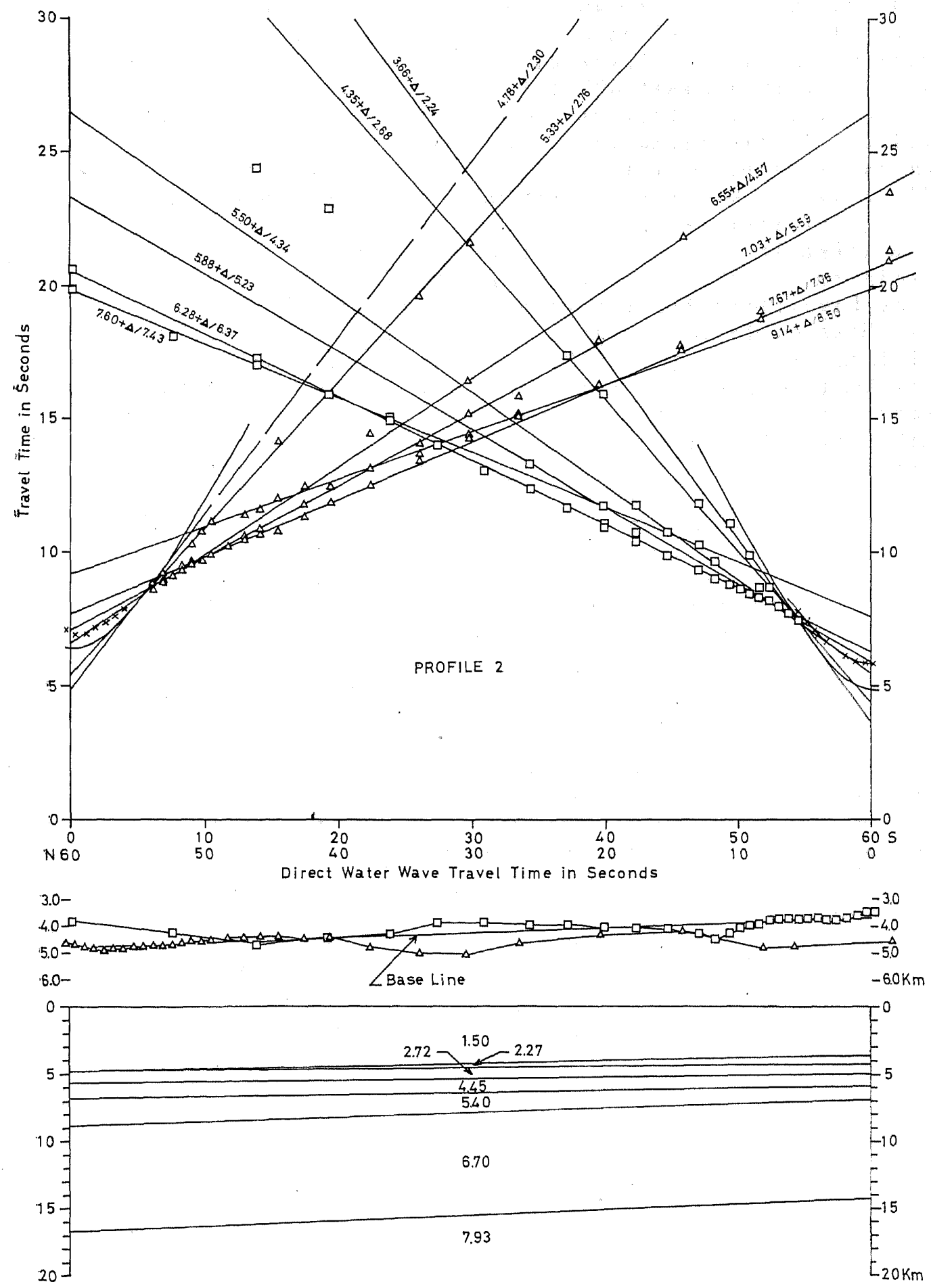

Fig. 6. Profile 2 
A Crustal Section across the Izu-Ogasawara Arc and Trench
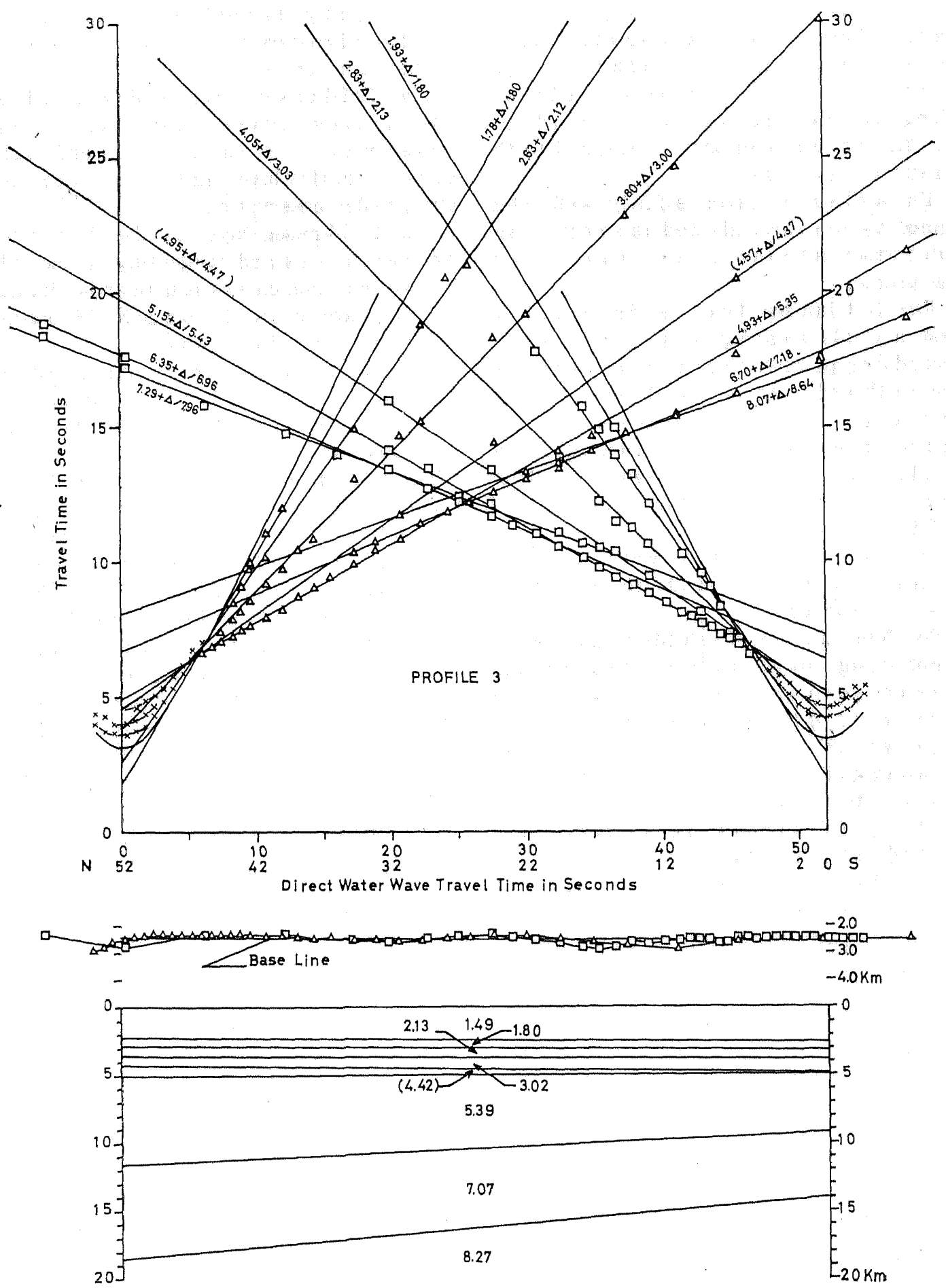

Fig. 7. Profile 3 
curve at the south end and by an assmued velocity line drawn tangent to the $R_{1}$ curve at the north end. The $2.72-\mathrm{km} / \mathrm{sec}$ layer probably represents the opaque sediments along the ridge side slope of the trench and the $2.27-\mathrm{km} / \mathrm{sec}$ layer may correspond to the stratified sediments.

The $4.45-\mathrm{km} / \mathrm{sec}$ layer is fairly well determined by first arrivals and tangency to the sub-bottom reflection curves at each end of the profile.

The $5.40-\mathrm{km} / \mathrm{sec}$ layer is determined by first arrivals recorded between 8.3 and 11.8 seconds range and several later arrivals at the north end. At the south end the three first arrivals recorded between 6.2 and 7.2 seconds range may originate from either the $5.40-\mathrm{km} / \mathrm{sec}$ or $4.45-\mathrm{km} / \mathrm{sec}$ layers. A few later arrivals are used to give the velocity line of $5.23-\mathrm{km} / \mathrm{sec}$ at this end.

The $6.70-\mathrm{km} / \mathrm{sec}$ layer is well determined by many good first arrivals and second arrivals at both ends.

The determination of velocity in the mantle is not straightforward. The time of arrivals recorded beyond 40 seconds range at the southern end of the profile plot systematically below the $6.37-\mathrm{km} / \mathrm{sec}$ apparent velocity line. A straight line fit of these arrivals and several later arrivals at shorter range give a velocity of $7.43-\mathrm{km} / \mathrm{sec}$ and a reverse point of 19.86 seconds. However, on the reverse half of the profile there are no corresponding first arrivals whose velocity line can produce agreement of reverse points, though several later arrivals within 40 seconds can do. Therefore, it is simply assumed that the refracted waves from the Moho were not observed at the north end. The reason for the failure to detect mantle refractions is not known.

PROFILE 3

This reversed profile was recorded over a deep-sea terrace located along the eastern flank of the Shichito-Iwojima ridge. The profile was positioned south of refraction profile 2 of LUDWIG et al. (1966). The topography is relatively smooth except for submarine canyon at the north end of the pro- file. A gently sloping base line between 2.36 and 2.57 kilometers depth was used for topographic corrections.

The $1.80-\mathrm{km} / \mathrm{sec}$ layer is determined by later arrivals recorded just before $R_{1}$ and tangency to the $R_{1}$ curve at each end. The thickness of this layer agrees well with seismic profiler observation.

The $2.13-\mathrm{km} / \mathrm{sec}$ layer is also determined by later arrivals and tangenting to the subbottom reflection curves at both ends. Similar velocities are obtained from a $\mathrm{X}^{2}-\mathrm{T}^{2}$ solution of sub-bottom reflection data.

The $3.02-\mathrm{km} / \mathrm{sec}$ layer is determined by later arrivals, particularly strong arrivals recorded at the north end, and the sub-bottom reflection data.

The $4.42-\mathrm{km} / \mathrm{sec}$ layer is determined by a few strong later arrivals recorded at the north end and by a few weaker later arrivals at the south end. Therefore, this layer is questionable and is designated by parentheses in the figure. If the $4.42-\mathrm{km} / \mathrm{sec}$ layer is omitted, the thicknesses of the $3.02-\mathrm{km} / \mathrm{sec}$ layer and the underlying $5.39-\mathrm{km} / \mathrm{sec}$ layer will increase by about 0.6 kilometers and 0.2 kilometers, respectively, at the north end.

The $5.39-\mathrm{km} / \mathrm{sec}$ layer is well determined by many first arrivals and later arrivals recorded at both the ends.

The $7.07-\mathrm{km} / \mathrm{sec}$ layer is well determined by many strong first arrivals. Some later arrivals are used to determine the velocity lines.

The $8.27-\mathrm{km} / \mathrm{sec}$ layer is fairly well determined by first arrivals recorded at each end. A some difficulty in velocity determination is caused by an arrival which plots high at the southern end. Except this arrival time, the mantle determination by this profile is the most reliable of the group.

PROFILE 4

This profile was recorded on the western flank near the crest of the Shichito-Iwojima ridge. It is difficult to determine the precise distance between shots and receiving positions, because direct water waves are not observed beyond 5 seconds range and the various reflected water waves are not readily identifi- 
A Crustal Section across the Izu-Ogasawara Arc and Trench
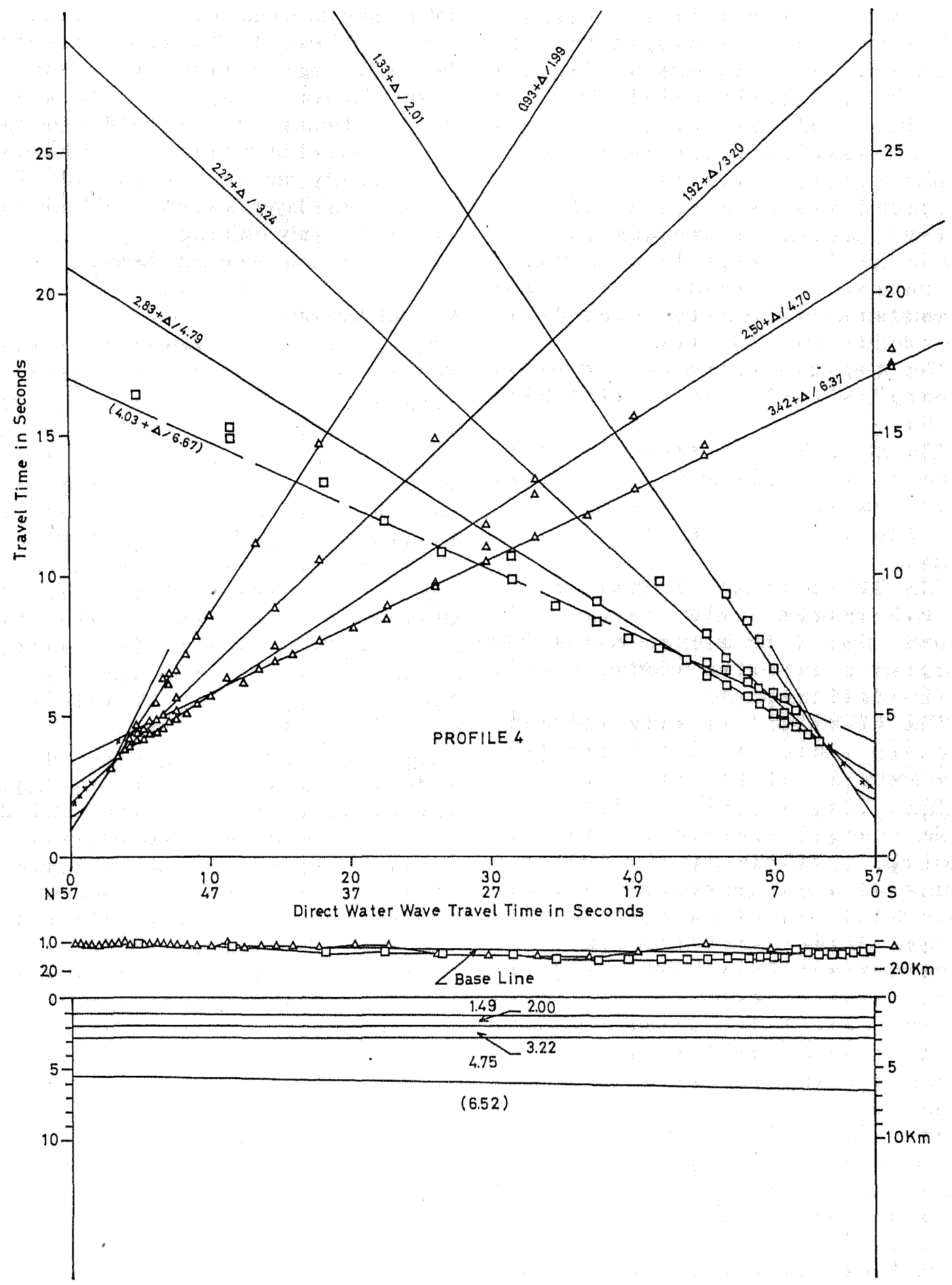

Fig. 8. Profile 4 
able. Moreover, considerable northward drift of the receiving vessels occurred during the recording. The large separation of shooting track introduces further difficulty in the calculations of distances based on reflection times, because the precise water depths at which the reflections occurred are not known. Calculated distances between the shots and receiving positions were compared with ship's navigation, i.e., speed and course. Because of the uncertainty in distance, the deduced crustal structure may contain some ambiguity in volocities and thicknesses.

Topographic corrections were applied to a sloping base line between 1.04 and 1.49 kilometers depth.

The $2.00-\mathrm{km} / \mathrm{sec}$ layer is determined by two first arrivals recorded at the north end and many later arrivals at both ends. Its velocity lines at each end are tangent to the $R_{1}$ curve.

The $3.22 \mathrm{~km} / \mathrm{sec}$ layer is based on later arrivals recorded at short distances. The velocity lines of this layer are controlled by tangency to sub-bottom reflection curves at both ends of the profile.

The $4.75-\mathrm{km} / \mathrm{sec}$ layer is governed mainly by many distinct first arrivals recorded at the north end and at the south end.

The $6.52-\mathrm{km} / \mathrm{sec}$ layer is somewhat questionable, although it is determined by many first arrivals. A velocity line of $6.37-\mathrm{km} / \mathrm{sec}$ is fairly well determined by many first arrivals recorded at the north end beyond 12 seconds range. On the contrary, it is difficult to fit first arrivals at the south end to a straight line, because of scatter. A tentative line drawn to give the least amount of scatter of first arrivals boyond 13 seconds range does not reverse with the $6.37-\mathrm{km} / \mathrm{sec}$ line. Because the arrivals recorded at long distance give approximately the same reverse point, the condition of reverse points would appear to be satisfied. The dashed line in the figure is based on reverse point condition, and gives a velocity of $6.67 \mathrm{~km} / \mathrm{sec}$. The several first arrivals recorded between 15 and 23 seconds range, that plot low, may be affected by topography under the receiving vessel. The last three data points plot above the line by about $0.4-0.5$ seconds. This may suggest that there is a large irregularity in the surface of the $6.52-\mathrm{km} / \mathrm{sec}$ layer along the profile. However, because of excessive drift of the receiving vessel at both ends, exact location of irregularity can not be established. The velocity in this layer is shown in parentheses, because it is only estimate.

Mantle arrivals were not observed.

\section{Acknowledgements}

The refraction measurements were made on board Konan-Maru No. 23 (Captain T. Shinozaki) and the Shii (Captain T. Sato) by S. Murauchi, N. Den, T. Asanuma, K. Hagiwara, and the author. The reflection profiling was made on board Konan-Maru No. 23 by S. Murauchi, N. Den, S. Asano, T. Asanuma, T. Yoshii, T. Sato, K. Hagiwara, M. Tajima, T. Watanabe, S. Ando, K. Tsuruoka, K. Takahashi, Y. Sakakibara, K. Mizuguchi, Y. Sawada, and the author. The work was greatly helped by the crew of the Konan-Maru No. 23 (The Nippon Suisan Fishery Co. Ltd.), especially by Chief engineers, G. Yanagiya, and S. Azuma.

The author's special appreciation is due to S. Murauchi and N. Den, for their encouragement and advice. Drs. N. Den and W. J. Ludwig critically read the manuscript and gave numerous suggestions for its improvement.

The work was supported by grants from the Government for one of the programs of the Upper Mantle Project, and the Japan Society for the Promotion of Science, as part of the U.S.-Japan Cooperative Science Program.

This paper was submitted to the Hokkaido University as a part of the author's doctoral thesis.

\section{References}

Den, N., A review of marine seismological research and an interpretation of crustal structure under the oceans (in Japanese), Jour. Seismol. Soc. Japan (Zisin), 15, 270-297, 1962.

Den, N., Crustal structures in the ocean and seas around Japan (in Japanese), Jour. Seismol. Soc. Japan (Zisin), 20, 131-134, 1967. 
Dietz, R. S., Marine geology of Northwestern Pacific: Description of Japanese bathymetric chart 6901, Bull. Geol. Soc. Am., 65, 1199-1224, 1954.

Dix, C.H., Seismic velocities from surface measurements, Geophysics, 20, 68-86, 1955.

Ewing, J. I., and G. B. Tirey, Seismic profiler, J. Geophys. Res., 66 (9), 2917-2927, 1961.

Ewing, J., and R. Zaunere, Seismic profiling with a pneumatic sound source, J. Geophys. Res., 69 (22), 4913-4915, 1964.

Ewing, J., M. Ewing, T. Aitken, and W. J. Ludwig, North Pacific sediment layers measured by seismic profiling, in The Crust and Upper Mantle of the Pacific Area, AGU Monograph 12, 147-173, 1968.

Heiskanen, W. A., and F. A. Vening Meinesz, The Earth and Its Gravity Field, McGraw-Hill, New York, 1958.

Hess, H. H., Major structural features of the Western North Pacific, an interpretation of $\mathrm{H}$. O. 5485 , bathymetric chart, Korea to New Guinea, Bull. Geol. Soc. Am., 59, 417-446, 1948.

Hotta, H., The structure of sedimentary layer in the Japan Sea (in Japanese), Bull. Hokkaido Univ., 18, 111-131, 1967.

Hotta, H., Stability of the crust-mantle structures and tectonics of the island arc and trench systems, Jour. Phys. Earth, 18 (in press), 1970.

Isacks, B., J. Oliver, and L. R. Sykes, Seismology and the new global tectonics, J. Geophys. Res., 73 (18), 5855-5899, 1968.

Iwabuchi, Y., Echograms of the deep sea floor South of Honshu, Japan (in Japanese), Geol. Mag., 69, 470-488, 1963.

Iwabuchi, Y., Topography of trenches east of the Japanese Islands (in Japanese), Geol. Mag., 74, 37-46, 1968.

Japanese Hydrographic Office, Explanatory Text of J. H. O. Bathymetric Chart 6302, 1966.
Katsumata, M., and L. R. Sykes, Seismicity and tectonics of the Western Pacific: Izu-MarianaCaroline and Ryukyu-Taiwan regions, J. Geophys. Res., 74 (25), 5923-5948, 1969.

Kosminskaya, I. P., S. M. Zverev, P. S. Veitsman, Yu. V. Tulina, and R. M. Krakshina, Basic features of the crustal structure of the Sea of Okhotsk and the Kuril-Kamchatka zone of the Pacific Ocean from deep seismic sounding data, Bull. Acad. Nauk, USSR, Geophys. Ser., 1, 11-27, 1963.

Le Pichon, X., Sea floor spreading and continental drift, J. Geophys. Res., 73 (12), 3661-3697, 1968.

Ludwig, W. J., J. I. Ewing, M. Ewing, S. Murauchi, N. Den, S. Asano, H. Hotta, M. Hayakawa, T. Asanuma, K. Ichikawa, and I. Noguchi, Sediments and structure of the Japan Trench, J. Geophys, Res., 71 (8), 2121-2137, 1966.

Mogi, A., The Izu Ridge (in Japanese), in Fossa Magna, Geol. Soc. Japan, 217-221, 1968.

Murauchi, S., N. Den, S. Asano, H. Hotta, T. Yoshii, T. Asanuma, K. Hagiwara, K. Ichikawa, T. Sato, W. J. Ludwig, J. I. Ewing, N. T. Edgar, and R. E. Houtz, Crustal structure of the Philippine Sea, J. Geophys. Res., 73(10), 3143-3171, 1968.

Officer, C. B., J. I. Ewing, J. F. Hennion, D. G. Harkrider, and D. E. Miller, Geophysical investigations in the Eastern Caribbean: Summary of 1955 and 1956 cruises, in Physics and Chemistry of the Earth, 3, 17-109, 1959.

Raitt, R. W., Oceanographic instrumentation, Nat. Res. Council Pub., 309, 70, 1952.

Shor, G. G., Refraction and reflection technique and procedure, in The Sea, 3, Interscience Publisheres, 20-38, 1963.

Tayama, R., On "Depth Curve Chart of the Adjacent Seas of Japan" (Chart 6901) (in Japanese), Hydr. Bull. Japan, 32, 160-167, 1952.

(Received Feb. 5, 1970) 